\section{Transient parotitis after upper gastrointestinal endoscopy}

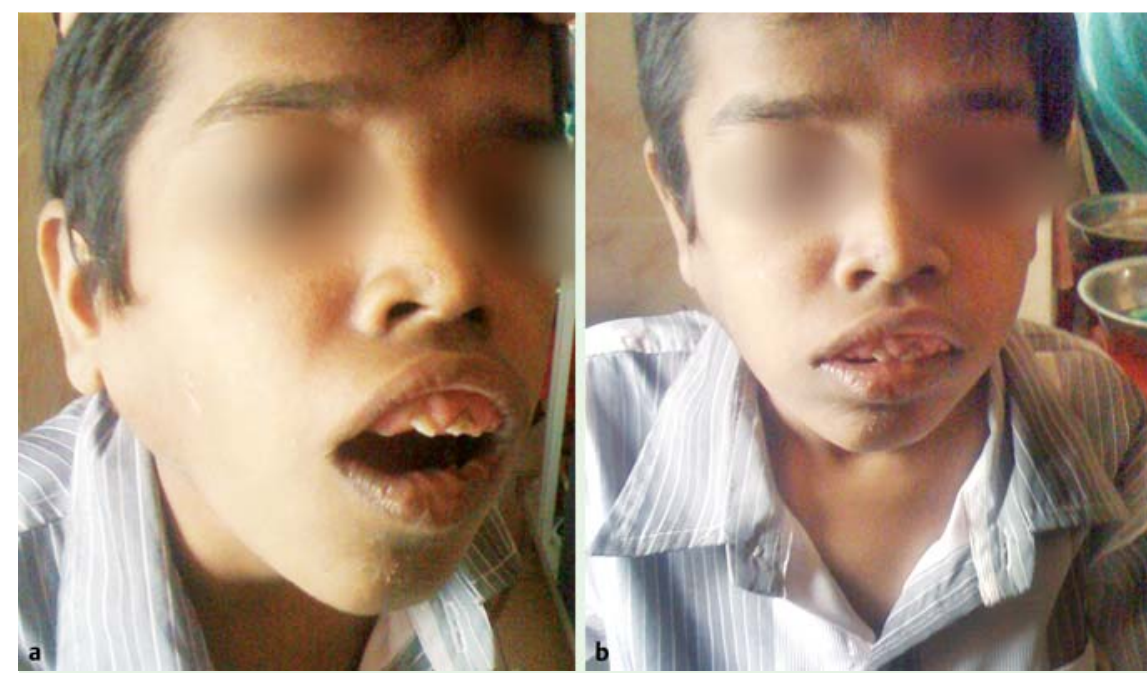

Fig. 1 a Right parotid enlargement in a 12-year-old boy with epilepsy and recurrent abdominal pain, who underwent endoscopy without topical anesthesia. b Facial view reveals bilateral parotid enlargement: the right is much more enlarged than the left side.

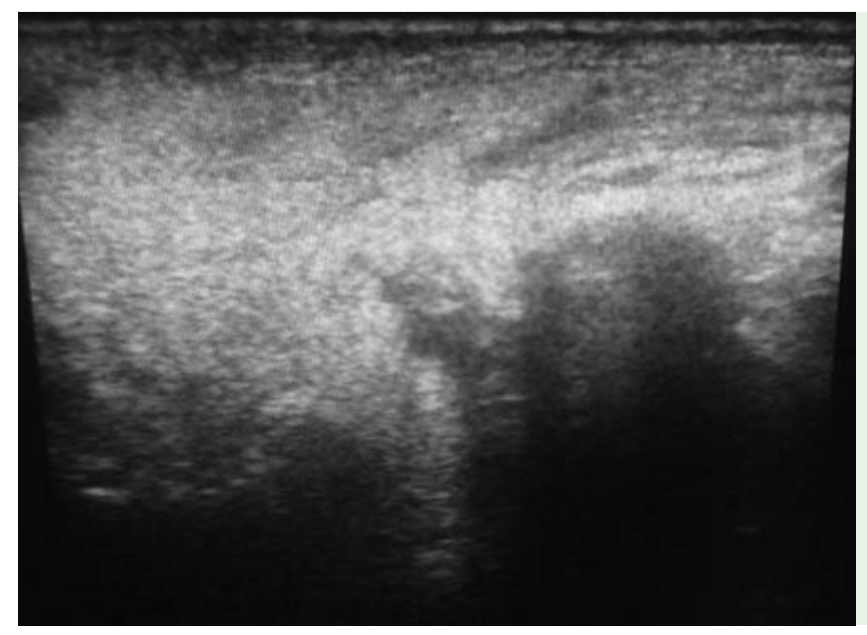

Fig. 2 Ultrasound view of the edematous right parotid.

A 12-year-old boy with epilepsy was referred for recurrent abdominal pain of 2 months duration and underwent endoscopy without conscious sedation. The patient strained a little during the procedure and antral gastritis was detected. After 2 minutes of having the procedure, he developed swelling of the right parotid gland ( Fig. 1). On examination, he had bilateral nontender, noncrepitant parotid enlargement without excess salivation, and gingival hyperplasia (phenytoin-induced) but was otherwise clinically normal. Ultrasound showed an edematous right parotid gland ( $\mathbf{F i g . 2}$ ); the left parotid was normal and the swelling congestion and salivary gland enlargement $[4,5]$. Couper hypothesized that head manipulation leads to obstruction of thoracic inlet, which further leads to parotid congestion [6]. Wakayama et al. postulated obstruction of the salivary ducts $[7,8]$, but this is unlikely to be a cause. Bonchek [3] and Strowbridge [9] considered a reflex arc, with an afferent stimulus from the tongue and oropharynx and efferent impulses through the glossopharyngeal nerve (parasympathetic) leading to vasodilatation and hyperemia. The main secretory parasympathetic innervation of the submandibular and sublingual glands comes from the salivary nucleus via the facial nerve, chorda tympani, and lingual nerve, and via the glossopharyngeal nerve to the parotids, which is not blocked by atropine.

Distension of the esophagus is a potent stimulus of salivation, as is chronic irritation [10], producing a greater response on the stimulated side but there is some effect on the opposite side too. Even if the stimuli on both sides are equal, the response may be stronger on one side than the other, explaining the asymmetrical parotid swelling in our patient. In summary, salivary gland enlargement is a rare complication of endoscopy that does not require specific medical management.

Endoscopy_UCTN_Code_CPL_1AH_2AJ

Competing interests: None

\section{S. Vadivel Kumaran, B. Sumathi, D. Nirmala Natarajan}

Department of Medical Gastroenterology, Madras Medical College, Chennai, India

\section{References}

1 Ziccardi V, Molloy PJ. Parotid swelling after endoscopy. Gastrointest Endosc 1992; 38: 520

2 Blackford RW. Recurrent swelling of parotid and submaxillary gland following bronchoscopy. Ann Otol Rhinol Laryngol 1974; 53: 54-64

3 Bonchek LI. Salivary gland enlargement during induction of anaesthesia. JAMA 1969; 209: $1716-1718$

4 Matsuki A, Wakayama S, Oyama T. Acute transient swelling of the salivary glands during and following endotracheal anaesthesia. Anaesthesist 1975; 24: 125-128

5 Attas M, Sabawala PB, Keats AS. Acute transient sialadenopathy during induction of anaesthesia. Anaesthesiology 1968; 29: 1050-1052 
6 Couper JL. Benign transient enlargement of the parotid glands associated with anaesthesia. S Afr Med J 1973; 47: 316-318

7 Wakayama S, Satone T, Jin T et al. 3 cases of salivary gland swelling developing during and immediately after general anaesthesia. Masui 1973; 22: 1417-1421

8 Slaughter R, Land Boyce HW. Submaxillary salivary gland swelling developing during peroral endoscopy. Gastroenterology 1969; 57: $83-88$

9 Strowbridge MNF. Acute salivary gland enlargement following instrumentation of the upper airway. J R Army Med Corps 1987; 133: $163-165$

10 Neil Jenkins $G$. The physiology and biochemistry of the mouth. 4 th edn. London: Blackwell; 1978
Bibliography

Dol http://dx.doi.org/

10.1055/s-0033-1344775

Endoscopy 2013; 45: E424-E425

(C) Georg Thieme Verlag KG

Stuttgart · New York

ISSN 0013-726X

Corresponding author

S. Vadivel Kumaran

Department of Medical Gastroenterology Madras Medical College

Chennai 600003

India

dr_valky@yahoo.com 